\title{
Result of ACL Injury Treated Arthroscopically with Single Transitibial Hamstring Band Autograft
}

\author{
Dr. Krunal Chaudhari ${ }^{1}$, Dr. Dipalkumar Rathod ${ }^{2}$, Dr. Harshal Damor ${ }^{3}$, Dr. Raghav Suthar ${ }^{4}$
}

Shardaben Hospital, Saraspur

\begin{abstract}
Injury to the anterior cruciate ligament (ACL) is one of the most devastating and frequent injuries of the knee. Surgical reconstruction is the current standard of care for treatment of ACL injuries in active patients. The widespread adoption of ACL reconstruction over primary repair was based on early perception of the limited healing capacity of the ACL. Although the majority of ACL reconstruction surgeries successfully restore gross joint stability, post-traumatic osteoarthritis is commonplace following these injuries, even with ACL reconstruction. The development of new techniques to limit the long-term clinical sequelae associated with ACL reconstruction has been the main focus of research over the past decades. The improved knowledge of healing has resulted in the discovery of novel biologically augmented ACL-repair techniques that have satisfactory outcomes in preclinical studies. This instructional review provides a summary of the latest advances made in ACL repair.
\end{abstract}

Keywords: arthroscopy hamstring ACL ethibond tibial tunnel femoral tunnel

\section{Introduction}

Knee joint is the most commonly injured one among all joints and anterior cruciate ligament (ACL) is the most commonly injured ligament. modern high speed vehicular trauma and sporting life style has led to increased ligament injuries of the knee. The anterior cruciate ligament forms the pivot in the functional congruence and stability of the knee in association with the other ligaments, capsule, muscles and bone.

The Anterior Cruciate ligament (ACL) is the primary stabilizer of the knee joint and prevents anterior translation of femure on tibia. It is also important in counteracting rotational and valgus stress. After ACL injury, most patients experience recurrent episodes of instability, pain and decreased function. ACL tears have been termed as the 'Beginning of the end of the knee'.

The word "Arthroscope" means Arthro- joint and scopy to see(to see the joint). Arthroscopy and arthroscopic surgery have grown rapidly on the last two decades and have changed our approach to management of joint injury and pathology. Arthroscopic reconstruction of torn ACL has become the gold standard in treating ACL tears. The surgical reconstruction of the anterior cruciate ligament with hamstring graft represents an attempt to reestablish knee kinematics.

Earlier open arthrotomy and reconstruction of the ACL was done using central third patellar tendon graft. However excessive soft tissue dissection lead to complications like increased post operative pain and increased infection rate. Complaints of post surgical knee stiffness and prolonged duration of rehabilitation were other complications that lead to the development of Arthroscopy assisted ACL reconstruction. The advantages were key hole incisions, less intense inflammatory response thus reducing the post op morbidity and early recovery to full range of motion and also less potential for functional imbalance. Also the posterior aspect of knee joint can be better visualized through the arthroscope which was not possible in earlier arthrotomy procedures.
Reconstruction of ACL allows the patient to return to a pre trauma activity level and delays the occurrence of associated meniscal injury and onset of osteoarthritis. The incidence of associated cartilage damage in acute tears is reported at 15 $40 \%$ whereas it increases to $79 \%$ in chronic tears. Reconstruction is also essential to restore the stability of the knee. A stable knee in turn prevents worsening of existing chondral lesions as well as occurrence of newer lesions.

Various surgical procedures and graft selections have been proposed for ACL reconstruction such as bone -tendon-bone (BTB), semitendinosus tendon (ST), iliotibial band, Achillis tendon tibialis anterior tendon, and quadriceps tendon and allografts. Among these the central third of patellar tendon and hamstring tendons have been the most common type of graft used. Bony fixation and mechanical strength may explain the success of the patellar tendon graft, whereas the use of a four - bundle semitendinosus- gracilis graft guarantees high graft strength and a clinical outcome similar to that found in BTB graft. Various mode of fixation are also available like transfixation device, endobutton, bioscrews, ligament staples etc.

In evaluation of the arthroscopic ACL reconstruction many methods evolved and still research is going to find a native knee kinemetics. In this study we are highlighting acl reconstruction by transtibial drilling for tibial tunnel preparation and using single bundle hamstring graft for $\mathrm{ACl}$ reconstrutiom.

\section{Anatomy of ACL}

\section{Anatomy}

In a normal adult the ACL averages about $4 \mathrm{~cm}$ in length and $1 \mathrm{~cm}$ in width. The ACL is a band of regularly oriented dense connective tissue that connects the femur and tibia. The ACL is attached to a fossa on the posterior aspect of the medial surface of the lateral femoral condyle above, and to a fossa in front of and lateral to anterior tibial spine below. It is surrounded by a mesentry like fold of synovium that originates from posterior area of the knee and completely envelopes both ACL and PCL. Thus, although the cruciate ligaments are intra articular they are also extra synovial. 


\section{International Journal of Science and Research (IJSR) \\ ISSN (Online): 2319-7064}

Index Copernicus Value (2013): 6.14 | Impact Factor (2014): 5.611

\section{Femoral Attachment}

The ACL is attached to a fossa on the posterior aspect of the medial surface of the lateral femoral condyle. The attachment is in the form of a segment of a circle, with the anterior border straight and posterior border convex. The long axis of femoral attachment is tilted slightly forward from the vertical, and the posterior convexity is parallel to the posteriorarticular margin of the lateral femoral condyle. The origin is $16-24 \mathrm{~mm}$ in diameter and is located well posterior in the intercondylar notch. The centre of this origin has been noted to be $15 \mathrm{~mm}$ from the 'Over the top position'.

\section{Tibial Attachment}

Distally at its attachment on the tibia, ACL passes beneath the transverse meniscal ligament and few fascicles of ACL may blend with the anterior attachment of the lateral meniscus. The tibial attachment is somewhat broader than the femoral attachment, being $11 \mathrm{~mm}$ wide and $17 \mathrm{~mm}$ in the antero-posterior direction. Tibial attachment forms a triangle with the apex directed posteriorly.

The ACL courses anteriorly, medially and distally across the joint as it passes from the femur to tibia. It seems to turn on itself in a slight outward (lateral) spiral. The ACL is not a singular cord but a collection of individual fascicles that fan out over a broad, flattened area. Within the ligament, these fascicles are divided into -

1) Anteromedial Band (AMB) - those fascicles originating at the proximal aspect of the femoral attachment and inserting at the anteromedial aspect of the tibial attachment.

2) Posterolateral Band (PLB) - the remaining bulk of fascicles that are inserted at the posterolateral aspect of tibial attachment. When the knee is extended, the PLB is tight and AMB is moderately lax and when the knee is flexed, the femoral attachment of the ACL assumes more horizontal orientation, causing the AMB to tighten and PLB to loosen.

The insertion area of ACL at its insertion site is 3.5 times greater than the mid-substance cross sectional area. This serves to minimize stress on ligament bone interface. The ligament bone attachment is by way of an incorporation of collagen fibers of the ligament within the mineralized bone. This change from flexible ligamentous tissue to rigid bone is mediated through a transition zone of fibro cartilage.

\section{Blood Supply}

Major blood supply arises from ligamentous branch of the middle artery, which is the principal arterial supply that enters in its upper third through synovial sleeve. The medial and lateral inferior genicular arteries also supply the ACL. The synovial membrane that forms an envelope around the ligament is richly endowed by blood vessels. Recently a significant and more important contribution from anterior vessels in the soft tissue and synovium from the region of retro-patellar fat pad has been described. There is a minimal blood supply from femoral attachment and nothing from tibial attachment.

\section{Nerve Supply}

The nerve supply comes from the posterior articular branch of the posterior tibial nerve. Small nerve fibers that are responsible for pain have also been observed in the substance of ACL and also serve the purpose of proprioception.

\section{Functions of ACL}

The ACL functions in concert with all other anatomical structures in and around the knee joint to control and limit the motion and to maintain both static and dynamic equilibrium.

ACL has two complementary roles:

1. Proprioception

2. Mechanical

The evidence of proprioception function comes mainly from extensive histological observations demonstrating proprioceptive nerve endings in the ACL.

The mechanical role as a tensile load carrying element has been characterized with considerable detail.

1) The ACL, principally the anteromedial band accounts for the resistance to anterior tibial translation on the femur with the knee in $90 *$ flexion.

2) The posterolateral portion provides the principal resistance to hyperextension.

3) It provides a check to internal axial rotation and thereby affords rotatory control of the knee.

4) It is a secondary restraint resisting both valgus and varus strains in all degrees of flexion.

5) Tension in the ACL fine tunes the 'SCREW HOME' movement stabilizing the joint as it approaches terminal extension.

The cruciate ligaments perform the contrasting function of permitting motion of the articular surfaces on one hand and restraining their motion on the other by offering resistance to certain forces. Excessive restraint of mobility leads to functional disability and unphysiologic loading of the ligaments, whereas deficient restraint leads to instability.
Mechanism of Injury
1) Abduction and valgus force
2) Rotation(internal or external)
3) Direct injury to knee
4) Dislocation of knee

\section{Pathoanatomy of Injury}

ACL may be injured at various places:

- From its femoral attachment(without avulsion of bone)

- From mid substance- it may be partial or complete tear

\section{Clinical Evaluation}

The clinical evaluation of a patient with suspected ACL injury starts with a good history of the mechanism of injury. A history of twisting injury to the knee i.e. internal rotation of femur on fixed tibia is the most common history. The commonest symptom is giving way of knee which is an expression of the 'axial instability'. Hearing or feeling of a pop is highly suggestive of the injury. Patient will be unable

\section{Volume 4 Issue 11, November 2015}




\section{International Journal of Science and Research (IJSR) \\ ISSN (Online): 2319-7064}

Index Copernicus Value (2013): 6.14 | Impact Factor (2014): 5.611

to continue his work or his sport following the injury. The patient complains of severe pain and swelling in the knee. With associated haemarthrosis the possibility of ACL injury is around 70\% (Pringle, 1917 \& Lucie, 1984).

\section{Signs Confirming the Diagnosis of ACL Injury}

\section{Anterior Drawer Test}

With the patient supine on the examining table, the hip is flexed to $45^{\circ}$ and the knee to $90^{\circ}$, placing the foot on the table top, the examiner sits on the dorsum of patient's foot to stabilize it and both hands are placed behind the knee to feel for relaxing of the hamstring muscles. The proximal part of the leg is then gently pulled and pushed repeatedly anteriorly and posteriorly noting the movement of the tibia on the femur. The displacement causes a palpable and audible jump on the joint known as Finochietto's jump sign. 75\% of the patients have ACL deficit.

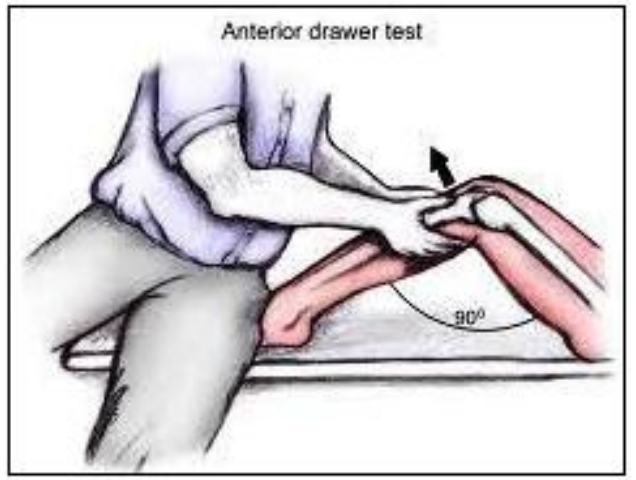

\section{Lachman Test}

The patient is placed supine on the examining table with the involved extremity positioned towards the examinees side. The involved extremity is kept in slight external rotation and the knee between full extension and $15^{\circ}$ of flexion. The femur is stabilized with one hand and firm pressure is applied to the posterior aspect of the proximal tibia, lifting it forward in an attempt to translate it anteriorly. One hand firmly stabilizes the femur while the proximal tibia is gripped in such a manner that the thumb lies on the anteromedial joint margin. When an anteriorly directed lifting force is applied by the palm and fingers, anterior translation of the tibia in relation to the femur can be palpated by the thumb. Anterior translation of tibia associated with a soft or a mushy end point indicates a positive test. When haemarthrosis, spasm from hamstring or torn meniscus prevent flexion of knee to $90^{\circ}$, Lachman's test is useful.

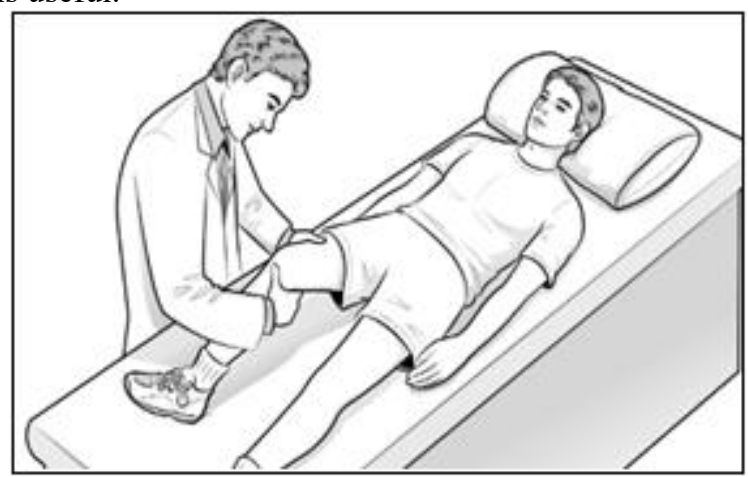

\section{Pivot Shift Test}

The foot is lifted with the knee extended and internally rotated. Valgus stress applied to the lateral side of the leg in the region of the fibular neck with the opposite hand and when the knee is slowly flexed while valgus and internal rotation being maintained, the tibia subluxates anteriorly. As the knee is flexed approximately 30 degrees, the iliotibial band passes posterior to the center of rotation of the knee and provides the force that reduces the lateral tibial plateau on the lateral femoral condyle. This is synonymous with anterolateral instability. When the knee is locked due to meniscal injury, it is difficult to examine. In such situation pivot shift test can be demonstrated easily when the patient is anesthetized.

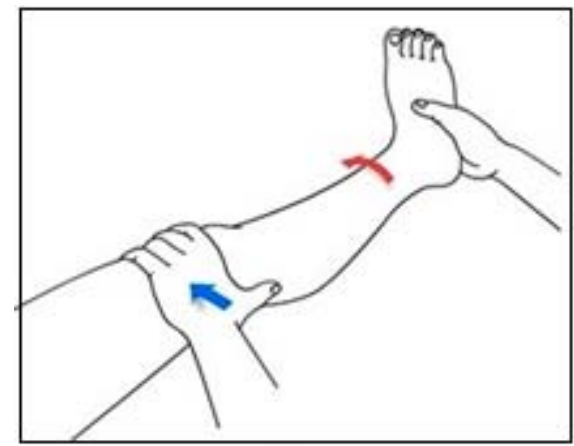

\section{Radiographic Signs}

SEGOND'S fracture is named from lateral capsular sign in which a fleck of bone is avulsed from the lateral articular surface of the tibia. The presence of notched deficit in the lateral femoral condyle is suggestive of chronic ACL injury. A cortical osseous fragment visualized anterior and superior to the tibial spine on the lateral $\mathrm{X}$ - ray indicate avulsion of ACL from its tibial insertion.

\section{MRI in ACL Injury}

Satellite images are most useful for evaluation of ACL, fiber orientation of the femoral and tibial attachments. Coronal images are useful for evaluation of the collateral ligaments and for assessing the signal characteristics of the ACL within the intercondylar notch. The ACL appears oriented like a 'hand in pocket coursing superolateral to anterior inferomedial. Axial views are used for assessment of ACL and posterior cruciate ligament in the notch, bone contusion, para articular fluid collections and the joint capsule.

T2 weighted water sensitive sequences are the most useful for evaluation of contusions, edema and hemorrhage seen in association with ACL tears.

\section{Normal ACL Appearance on MR imaging:}

ACL has "Propeller" or "fanlike" configuration gray, slightly inhomogeneous signal intensity may be seen in the normal ligament and the ligament may not be seen in its entity on a single sagittal slice.

\section{In injured ACL:}

In Acute ACL tears - Poor (or) Non visualization of the ACL on sagittal images, an amorphous edematous mass with focally increased Signal on T2 - weighted images, is observed. 


\section{International Journal of Science and Research (IJSR) \\ ISSN (Online): 2319-7064}

Index Copernicus Value (2013): 6.14 | Impact Factor (2014): 5.611

In chronic ACL tears:

Although acute tears can accurately be differentiated from intact ligaments, chronic tears may have potentially confusing appearances due to bridging fibrosis, which resembles the normal ACL. The researchers found that the most useful MR imaging features for diagnosis of an acute ACL tear was edematous soft tissue in the intercondylar notch. Nonvisualization of the ACL was uncommon with chronic tears. The most useful finding in differentiating chronic tears is abnormal course and focal angulation of the ligament without edema.

\section{Operative Technique}

An informed consent was taken from the selected patients after explaining the procedure, its outcome, complications and the prolonged rehabilitation protocol to be followed subsequently.

\section{Preoperative Period}

After pre-anaesthetic check-up, a single dose of a third generation cephalosporin (ceftriaxone; $1 \mathrm{gm}$ ) and aminoglycoside (amikacin; 500mg) was administered intravenously about half an hour prior to procedure.

All our scopies were carried out under spinal anaesthesia and under tourniquet control. Averagr time for surgery is $1^{1 / 2}$ to 2 hours. For anaesthesia we had used sensorcaine.

Anaesthetized patient is taken on table and tourniquet and leg holder are applied. The limb is thoroughly scrubbed and surgically prepared from toes to tourniquet. The foot end of table is dropped so that the drapped limb will dangle at $90^{\circ}$.

\section{Types of Grafts}

There are various types of grafts:

1. Autografts

2. Allografts

3. Synthetic materials

1. Autografts:

- Semitendinosus tendon

- Gracilis tendon

- Patella tendon

- Quadriceps tendon

- Achillis tendon

- Iliotibial band

- Plantaris tendon

- Tibialis posterior tendon

\section{Allografts}

- Patellar tendon

- Semitendinosus tendon

- Quadriceps tendon

- Tibialis anterior tendon

\section{Synthetic grafts:}

Most commonly used grafts are:

- Trevira ligament

- Gore-Tex ligament

- Stryker ligament

- Leeds-keio ligament

- Profex ligament

- Carbon fiber prosthesis

Various graft and their biomechanical tensile strength are as below. We used semitendinosus-garcilus tendon as a quadrepled hamstring graft in our study.

\begin{tabular}{|c|c|c|c|c|c|}
\hline Tissue & $\begin{array}{l}\text { Ultimate Tensile } \\
\text { Load }(N)\end{array}$ & $\begin{array}{l}\text { Stiffness } \\
(\text { N/MM })\end{array}$ & $\begin{array}{c}\text { Cross Sectional } \\
\text { Area } \mathrm{mm}^{2} \\
\end{array}$ & Advantages & Disadvantages \\
\hline Intact ACL & 2160 & 242 & 44 & & \\
\hline $\begin{array}{c}\text { Bone-patellar- tendon } \\
\text { bone }(10 \mathrm{~mm})\end{array}$ & 2977 & 620 & 35 & Bone to bone healing & $\begin{array}{l}\text { Anterior knee pain,larger } \\
\text { incision }\end{array}$ \\
\hline Quadrupled hamstring & 4090 & 776 & 53 & $\begin{array}{c}\text { Small incision, less anterior knee } \\
\text { pain }\end{array}$ & $\begin{array}{l}\text { Hamstring weakness, soft tissue } \\
\text { healing, bone tunnel widening }\end{array}$ \\
\hline Quadriceps tendon & 2352 & 463 & 62 & Bone-to- bone & Anterior knee pain \\
\hline
\end{tabular}

\section{Graft Harvest}

- A longitudinal skin incision of about $4 \mathrm{~cm}$ is kept centered approximately $4 \mathrm{~cm}$ medial and just distal to the tibial tubercle or about three finger width below the medial joint line.

- Pes anserinus is exposed.

- Sartorius aponeurosis, gracilis tendon and semitendinosus tendons are identified. In gracilis and semitendinosus tendons, more proximal and thicker tendon is that of gracilis.

- Short incision is kept proximal to gracilis tendon.

- Insertion of both gracilis and semitendinosus are released subperiosteally, sutures passed through ends and tendons are pulled forward.

- Both tendons are freed from fibrous extensions to surrounding structures with help of scissors proximally up the thigh,
- Open -end stripper was passed over the tendon one by one and advanced carefully in line with it giving firm, steady but gentle pressure and simultaneously applying countertraction using the previously placed suture. Gracilis usually had a more muscular appearance after harvesting.

- In our patients, many times only semitendinosus is sufficient to create four strands. There may be no need to harvest gracilis tendon.

- Fold both tendons in half to form four strands.

- Place an ethibond no. 5 through loop end of both ends.

\section{Graft Preparation}

- Take the harvested graft on graft preparation board.

- They are stripped off their residual muscle fibers proximally using the blunt end of scalpel blade.

- Fold tendon loops on it tomake it four stranded . 


\section{International Journal of Science and Research (IJSR) \\ ISSN (Online): 2319-7064}

Index Copernicus Value (2013): 6.14 | Impact Factor (2014): 5.611

- Then, four strands are sutured with vicryl no. 2-0 with each other.

- Graft is passed through various holes in the graft sizer.

- Slight resistance should be felt as graft is pulled through sizer.

- Usual diameter of graft is 6-8 $\mathrm{mm}$ in our Indian patients.

- Ends of graft are fixed with ethibond no.2 sutures in a Chinese finger trap configuration.

- Graft is pretensioned manually and then on graft preparation board.

- Minimum, $24 \mathrm{~cm}$ of graft length should be available.

\section{Arthroscopy:}

- Arthroscope is introduced and knee is examined systematically in the 'W sequence, starting from the suprapatellar pouch, then the patellofemoral joint, medial gutter, medial meniscus, intercondylar notch, lateral meniscus and lateral gutter after making high anterolateral portal.

- Once all the pathologies are recorded a second anteromedial portal (working portal) is made at $1 \mathrm{~cm}$ distal to joint line and $1 \mathrm{~cm}$ medial to patellar tendon. All associated pathologies are dealt with appropriately like partial menisectomy for a meniscal tear that is unstable to probing, chondral defect shaving and removal of loose bodies.

\section{Notch Preparation:}

- A torn ACL is usually visualized as failing to extend to its normal femoral attachment (empty lateral wall sign).

- The remaining ACL tissue is removed using the basket forcep.

\section{Notchplasty:}

Initially, it was believed that notchplasty is a must procedure but now concept has been changed. If not indicated, it may not be done or it may be done at following stages of ACL reconstruction.

- If an osteophyte in notch is found artheoscopy, it should be immediately removed.

- After tibial tunnel placement, if one found that notch is impinging at that time notchplasty can be done.

- Before femoral tunnel placement, if attachment of ACL on femoral condyle can not be optimally visualized.

- After insertion of graft, impingement on graft present, notchplasty can be done, but there are chances of graft injury.

- Notch should look like an inverted U shape.

\section{Tibial Tunnel Preparation}

\section{TIBIAL TUNNEL}

- The acufex tibial guide is introduced into the joint through the anteromedial portal after setting the inclination of the zig at 55 degrees.

- The aimer is placed on the center of the tibial foot print which lies about $7 \mathrm{~mm}$ anterior to the PCL in the midpoint and just medial to the posterior edge of the anterior horn of lateral meniscus.
- The sleeve is inserted into the guide upto the tibial cortex( through the incision used for graft harvesting) at about $2 \mathrm{~cm}$ medial to the tibial tubercle and $4 \mathrm{~cm}$ below the joint line. A guide pin is drilled into the joint through the sleeve.

- The tunnel is then reamed with a cannulated headed reamer placed over the guide pin, starting from $8 \mathrm{~mm}$ size upto the size determined by graft sizer.

\section{FEMORAL TUNNEL}

- Femoral offset guide is introduced into the joint through the tibial tunnel and engaged into "over the top" position with the knee in $90^{\circ}$ flexion. The guide is aimed at 2 o'clock position in the left knee and 10 o'clock in the right knee.

- An appropriate sized offset guide is used so as to leave about $2 \mathrm{~mm}$ of posterior cortical wall after drilling the femoral tunnel ( $7 \mathrm{~mm}$ size for $10 \mathrm{~mm}$ reamed tunnel).

- The guide pin is then drilled through the intercondylar region and lateral femoral cortex to emerge out of the anterolateral aspect of the thigh.

- An appropriate sized cannulated calibrated reamer is threaded over the pin and femoral tunnel reamed upto the $40 \mathrm{~mm}$ mark on the calibrated reamer. The sharp edges of the femoral tunnel were smoothened by shaver and debris removed.

\section{Graft Placement And Fixation}

- Insert $2.7 \mathrm{~mm}$ drill guide for endobutton through tibial and femoral tunnel and out through femoral cortex.

- Pass $4.5 \mathrm{~mm}$ endobutton drill bit over it.

- Now remove pin and drillbit and measure length of femoral tunnel

- Now fix mercillin tape to endobutton at one end and to graft at another end.

- Length of this tape is-Total lenth of femoral tunnel-graft length $(25 \mathrm{~mm})$

- Now, pass ethibond no.2 through one hole and ethibond no. 5 in another hole of endobutton.

- Pass a drill guide which carries suture in its eye and pass it through tibial tunnel, femoral tunnel and out through anterolateral femoral cortex.

- With the help of sutures pull graft into tunnel to rotate endobutton in place at this time pull graft distally for 3 minutes.

- The distally oriented sutures are firmly tensioned and then tied around a tibial suture post.

- Knotting is usually achieved at $20-30^{\circ}$ of knee flexion.

- Check the knee through full range of motions to chek for impingement of graft.

- Check the stability by Lachman's test.

- Remove sutures from thigh.

- Closure done in layers.

- A sterile dressing is applied. After applying a pressure bandage, tourniquet deflated and tourniquet time noted. Knee is subsequently placed in a brace locked in extension 


\section{International Journal of Science and Research (IJSR) \\ ISSN (Online): 2319-7064}

Index Copernicus Value (2013): 6.14 | Impact Factor (2014): 5.611
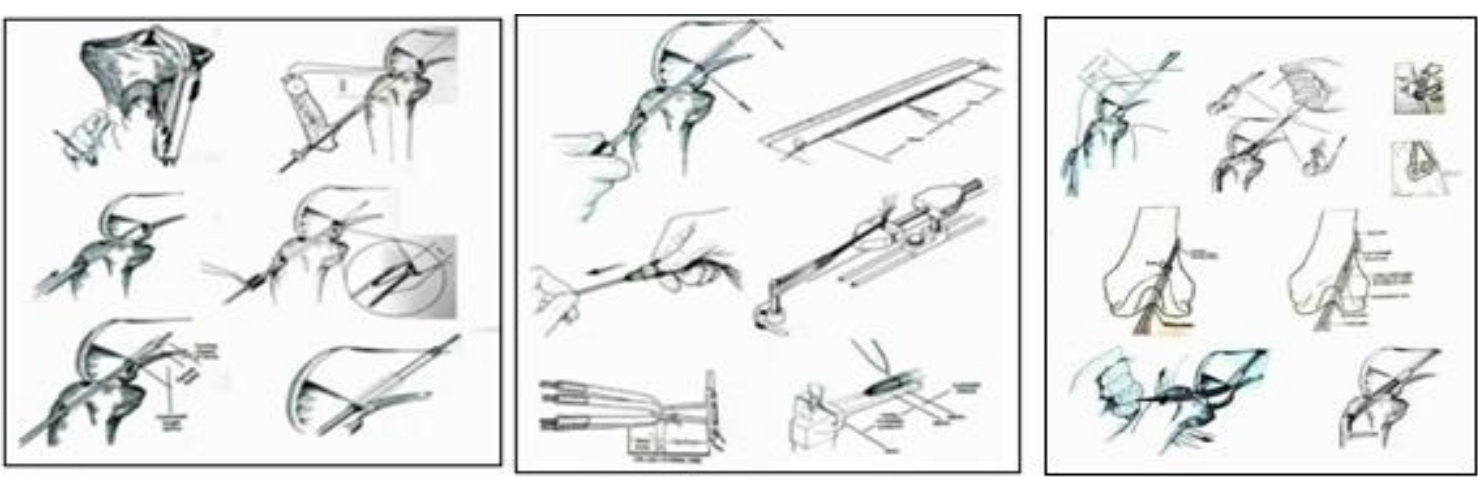

\section{POSTOPERATIVE CARE}

Patient was encouraged to lie supine with foot end elevated for 24 hours, as spinal anaesthesia was given during procedure. He was encouraged to use ice packs to reduce the swelling. Round the clock analgesia (initially i.v., later oral) was administered to assist in physiotherapy. Wound inspection was done on 3rd postoperative day. Only if the wound was healthy and patient's compliance for physiotherapy was assured, the patient was discharged on oral antibiotics. Sutures were removed on 14th postoperative day.

\section{ACL Rehabilitation Programme}

\begin{tabular}{|c|c|}
\hline Immobilization & \\
\hline Knee braced locked at zero when not doing exercises & 2 weeks \\
\hline Brace removed during day time & 2-4 weeks \\
\hline Brace locked at $0^{0}$ while sleeping & 4 weeks \\
\hline Ambulation & \\
\hline Two crutch ambulation in knee brace,weight bearing as tolerated & Immediate \\
\hline Remove brace but continue crutches & 2-4 weeks \\
\hline Discontinue crutches when quadriceps contol is acquired and lack of extension is less than $10^{\circ}$ & 4-6 weeks \\
\hline Range of motion(out of brace) & \\
\hline Early range of motion encouraged & \\
\hline Passive extension to full extension with untreated leg assisting & Immediate (as tolerated) \\
\hline Passive extension with weighted assistance & Immediate (as tolerated) \\
\hline Patellar mobilization & $1-8$ weeks as needed \\
\hline Stationary bicycle & 3-4 weeks \\
\hline Strength return & \\
\hline Quadriceps & \\
\hline Quadriceps : Co-contraction with hams & Immediate \\
\hline Leg raises: Bent knee raise with co-contraction & 2-6 weeks \\
\hline Knee dips with adduction squeeze & 3 weeks \\
\hline Wall sits & 3 weeks \\
\hline Stairmaster & 4 weeks \\
\hline Step up & 5 weeks \\
\hline Lunges & $8-10$ weeks \\
\hline Step down & $10-14$ weeks \\
\hline Hamstrings & \\
\hline Ham sets/slides & first week \\
\hline Resisted ham curls & 2-3 weeks \\
\hline Resisted hip extension & 2-8 weeks \\
\hline Resisted hip flexion & After 900 knee flexion is achieved \\
\hline Lower extremity conditioning & \\
\hline Isometric abduction and adduction & $1-8$ weeks \\
\hline Machine hip abduction and adduction & 3 weeks \\
\hline Calf strengthening & After 900 knee \\
\hline Road bicycle & flexion is achieved 4-5 months \\
\hline Functional exercise & \\
\hline Weight shift & 1 week \\
\hline Weight shift on trampoline & 3 weeks \\
\hline One leg bounce(supportd) & 4 weeks \\
\hline Form walking, gait evaluation & 4 weeks \\
\hline Slide board & 4 months \\
\hline Return to activity & \\
\hline Jogging & 4 months \\
\hline Straight line running & 5 months \\
\hline Directional changes/sport-specific adaptation & 6 months \\
\hline
\end{tabular}

Volume 4 Issue 11, November 2015 


\section{International Journal of Science and Research (IJSR) \\ ISSN (Online): 2319-7064 \\ Index Copernicus Value (2013): 6.14 | Impact Factor (2014): 5.611}

\section{Material and Method}

We have done pilot study of 100 cases of Arthroscopic ACL reconstruction by trans-tibial single bundle Hamstring Graft Technique.

Recently we have started to do arthroscopic ACL reconstruction with single mid bundle trans portal technique with quadrepuled semitendinosus graft to compare our own results of this technique with the time tested trans tibial technique. We have conducted this study.

\section{Age incidence}

\begin{tabular}{|c|c|}
\hline Age (In Years) & No. of patient \\
\hline $10-19$ & 6 \\
\hline $20-29$ & 41 \\
\hline $30-39$ & 33 \\
\hline $40-49$ & 16 \\
\hline $50-59$ & 4 \\
\hline$>60$ & 0 \\
\hline
\end{tabular}

- Age - 16Year Maximum Age - 58 Years

- ACL injuries were most common in young active individuals $(74 \%$ of total cases belongs to age between $20-40$ year)

2. Sex

\begin{tabular}{|c|c|}
\hline Sex & No. of Patient \\
\hline Male & 90 \\
\hline Female & 10 \\
\hline
\end{tabular}

- Males were affected in $90 \%$ of cases and female in rest $10 \%$

- More strenuous activities \& Increased incident of high velocity accident explains male predominance in ACL tear. Most of them are young bikers with slip from a bike or having collision with other vehicle and fall of weight on valgus externally rotated knee.

\section{Injury site}

\begin{tabular}{|c|c|}
\hline Injured Site & No. of patient \\
\hline Right & 54 \\
\hline Left & 46 \\
\hline
\end{tabular}

- 54 among the 100 patient had right sided injury \& 46 had left sided injury so ACL involvement on both side is almost equal.

\section{Occupation}

\begin{tabular}{|c|c|}
\hline Type of work & No. Patients \\
\hline Heavy & 2 \\
\hline Moderate & 24 \\
\hline Sedentary & 74 \\
\hline
\end{tabular}

- Most of patients in our study were sedentary worker and encountered ACL injury due to RTA and not related to their occupation.

\section{Mechanism of injury}

\begin{tabular}{|c|c|}
\hline Mechanism of injury & No. of patient \\
\hline RTA & 53 \\
\hline Fall down & 27 \\
\hline Sports & 18 \\
\hline Other & 2 \\
\hline
\end{tabular}

- Road traffic accident found to be more common followed by fall down and sports.

\section{Special Test Positive}

\begin{tabular}{|c|c|}
\hline Special Test & No of patient \\
\hline Lachman's & 92 \\
\hline Anterior Drawer Test & 86 \\
\hline Pivot Shift Test & 98 \\
\hline Mac- Murray'Test & 10 \\
\hline Varus/Vulgus & 5 \\
\hline
\end{tabular}

- To diagnose ACL insufficiency we have found that examination under anaesthesia is the most correct method . among all the test Lachman's test and Pivot shift test are positive in 92 and 98 percent respectively. In rest of the cases we have found arthroscopically that patients had either had locked bucket-tear (L.M. /M.M.) or the torned ACL stump was stucked to the PCL.

- Anterior drawer test is affected either by increased muscle tone of hamstring in apprehensive patients. It may be false positive in PCL / PLC insufficiency.

- In hyperlaxed joints to check the insufficiency its mandatory to check the normal joint first.

6. Associated Injury

\begin{tabular}{|c|c|}
\hline Associated Injury & No. of patient \\
\hline Medial Meniscus & 12 \\
\hline Lateral Meniscus & 10 \\
\hline Both menisci & 3 \\
\hline PCL & 1 (Grade 2$)$ \\
\hline LCL & 2 \\
\hline PLC & 3 \\
\hline MCL & 4 \\
\hline Cartilage damage & 5 \\
\hline
\end{tabular}

- Menisci are commonly involved with ACL injury and among them Medial meniscus is commonly involved.

\section{Observation and Analysis}

The following observations made

\section{Complications}

\begin{tabular}{|c|c|}
\hline Post Operative Complication & No. of patient \\
\hline Infection & 7 \\
\hline Haemarthrosis & 5 \\
\hline Graft site Complications & 2 \\
\hline Ligamentous Injury & 0 \\
\hline Other Complications & 0 \\
\hline
\end{tabular}




\section{International Journal of Science and Research (IJSR) \\ ISSN (Online): 2319-7064 \\ Index Copernicus Value (2013): 6.14 | Impact Factor (2014): 5.611}

- Infection was noted among the 7 patients and 5 of it occurred during immediate post op period and due to sensitivity to Ethibond controlled by antibiotic. Debridement done in 1 patient and after that infection resolved and In 1 patient removal of implant was needed after 8 month of debridement to control infection.

- Haemarthrosis noted in 5 patients in immediate post operative period which was resolved by anti inflammatory, Ice application and rest.

- Graft site tingling and numbness noted in 2 patient may be due to injury to cutaneous nerve.

\section{Follow up Period}

\begin{tabular}{|c|c|}
\hline Follow up period & Number of patient \\
\hline 6 month - 1 year & 8 \\
\hline 1 year - 2 year & 11 \\
\hline 2 year -3 year & 36 \\
\hline 3 year - 4 year & 28 \\
\hline 4 year - 5 year & 17 \\
\hline
\end{tabular}

- Shortest Follow up period - 6 and half month.

- Longest Follow up period - 4 year and 8 month

\section{Subjective Evaluation}

\begin{tabular}{|l|c|c|}
\hline \multirow{2}{*}{ Subjective Complain } & \multicolumn{2}{c|}{ No. of Patients } \\
\cline { 2 - 3 } & Pre-op & Post-op \\
\hline Pain & 100 & 12 \\
\hline Swelling & 97 & 10 \\
\hline Catching / Locking & 70 & 6 \\
\hline Instability & 76 & 4 \\
\hline Unable to sit crossed leg & 68 & 3 \\
\hline Unable to squat & 72 & 3 \\
\hline Difficulty in climbing Stairs & 65 & 6 \\
\hline Difficulty in walking & 60 & 2 \\
\hline
\end{tabular}

- Most common complain were pain, swelling and instability most of symptoms resolved after surgery.

\section{Clinical assessment according to grades :}

\begin{tabular}{|l|c|c|}
\hline \multirow{2}{*}{ Clinical test } & \multicolumn{2}{|c|}{ No. of Patient } \\
\cline { 2 - 3 } & Pre-op & Post-op \\
\hline Lachman's & 92 & 5 \\
\hline Anterior drawer & 85 & 3 \\
\hline Pivote shift & 98 & 2 \\
\hline
\end{tabular}

- After ACL reconstruction Lachman's was positive in 5 patients all having grade 1 laxity.

\section{Activity Level}

\begin{tabular}{|c|c|}
\hline Subjective Evaluation & No. of patient \\
\hline Normal & 83 \\
\hline Reduced & 15 \\
\hline Worse & 2 \\
\hline Same & 0 \\
\hline
\end{tabular}

- Most of the patients could able to do routine activity within 1 month and sports activity within 6 month
- Average hospital stay was only of 2-3 days in the most post operative patient. Physiotherapy started on $2^{\text {nd }}$ post operative day and partial weigh bearing started average on $5^{\text {th }}$ to $6^{\text {th }}$ post operative day. Full weight bearing was started average after 15 days.

- Quadriceps wasting was commonly seen in patient with chronic ACL insufficiency with larger injury-operation interval and with other ligamentous injury. Which affect the rehabilitation program and final outcome of muscle is low.

\begin{tabular}{|c|c|c|}
\hline \multicolumn{3}{|c|}{ Result Based on Lysholm Scale } \\
\hline Group & Result & No. of Patient \\
\hline A $(100-90)$ & Excellent & 79 \\
\hline B $(89-80)$ & Good & 15 \\
\hline C $(79-70)$ & Fair & 4 \\
\hline D $(69-60)$ & Poor & 2 \\
\hline E $(59-50)$ & Worst & 0 \\
\hline
\end{tabular}

- IN $94 \%$ of patients we have excellent to good outcome with 4 patient having fair results 2 of them having rotational instability due to the posterolateral corner insufficiency 1 having LCL laxity and 1 patient having hyperlaxed joint. Poor results obtained in one patient due to infection and early removal of implant done at 6 months and one patient had a posterolateral corner insufficiency.

- All patients had at final follow-up had excellent to good range of motion with no extension leg except only two patient having flexion deformity due to associated arthritis.

- Out of 26 patients with heavy to moderate work all yielded excellent results so results of ACL reconstruction are good in young active patients. The fair and poor results patients have sedentary lifestyle.

- In this series result, Arthroscopic ACL reconstruction is evaluated by Lysholm scale which is based on subjective Symptoms like pain, swelling, limping, catching, locking, sensation of giving away, whether patient need support or not, whether patient can able to climb stair or squat.

\section{Conclusion}

From the series following conclusion can be made

- ACL Injuries are common in young individual between 20-40 year of age (74\%).

- Males are more commonly affected $(90 \%)$

- Both knees are almost equally affected with slight predominance on right side $(54 \%)$

- RTA is more common cause of ACL tear (53\%) followed by Fall down (27\%) and sports (18\%).

- Excellent results in all patients having moderate to heavy workers $(26 \%)$ so patients with active lifestyle have favorable outcome.

- 74 out of 100 patients are sedentary workers and most of them are young bikers ACL injury encountered due to slip from bike or collision injury with other vehicle and fall of bodyweight in valgus externally rotation position.

- Results are excellent in patients having sole ACL injury or with ACL with meniscus injury.

- ACL reconstruction results with this method are fair to poor in patients having rotational instability with 


\section{International Journal of Science and Research (IJSR) \\ ISSN (Online): 2319-7064 \\ Index Copernicus Value (2013): 6.14 | Impact Factor (2014): 5.611}

posterolateral corner insufficiency (grade 1 to 2 ) and in patients with physiologically hyperlaxed joints.

- In this series excellent result obtained in $79 \%$ of cases, Good result obtained in $15 \%$ of the cases.

- Arthroscopic anterior cruciate ligament reconstruction reduces postoperative morbidity and enables early rehabilitation.

So from this series it can be concluded that Trans-Tibial Single Bundle Hamstring Graft Technique has yielded excellent to good (94\%) result for ACL reconstruction.

\section{References}

[1] Andersson, C.;Ondensten, M.,Good and Gillquist SURGICAL OR NON SURGICAL TREATMENT OF ACUTE RUPTURE OF ANRERIOR CRUCIATE LIGAMENT. A RANDOMIZED STUDY WITH LONG TERM FOLLOW UP. VOL. 71-A, NO. 1,AUGUST 1989, pp.965-974, Journal of Bone and Joint Surgery.

[2] Bonasia DE, Dettoni F, Bruzzone M, Bertolo C, Rossi R. Single bundle anatomic anterior cruciate ligament reconstruction: Indications, technique and results. OA Sports Medicine 2013 Aug 01;1(2):13.

[3] Ciccoti, M.G.,Lombardo,S.J., Nonweiler, and Pink,M. NON- OPERATIVE TREATMENT OF RUPTURE OF ANTERIOR CRUCIATE LIGAMENT IN MIDDLE AGED PATIENTS. RESULTS AFTER LONG TERM FOLLOW UP. VOL. 76-A, NO. 9,SEPTEMBER 1994, pp.1315-11321, Journal of Bone and Joint Surgery.

[4] Dye, S.F : The future of the anterior cruciate ligament Reconstruction Clin. Orthop.,325: 130-139, 1996.

[5] Hong-Chul Lim, Yong-Cheol Yoon, Joon-Ho Wang, , Ji-Hoon Bae, Anatomical versus Non-Anatomical Single Bundle Anterior Cruciate Ligament Reconstruction: A Cadaveric Study of Comparison of Knee Stability.

[6] Howell, S.M. and Taylor, M.A : Brace free rehabilitation with early return to activity, for knees reconstructed with double looped semitendinosus and gracilis graft, Bone and Joint Surgery. 78-A:814-825, June 1996.

[7] Johnson, R.J. , Beynnon B.D., Nichols , C. E Renstrom,P.A.F.H CURRENT CONCEPTS REVIEW THE TREATMENT OF INJURIES OF THE ANTERIOR CRUCIATE LIGAMENT VOL. 74-A, NO. 1,JANUARY 1992, pp.140-151, Journal of Bone and Joint Surgery.

[8] Johnson, R.J. ; Eriksson,E.; Hagrmark, T.; and Pope, M.H.:Five to ten year follow up evaluation after reconstruction of the anterior cruciate ligament . Clin Orthop. 183: 122-140,1984.

[9] Jones KG. Reconstruction of the anterior cruciate ligament. A technique using the central one-third of the patellar ligament. J Bone Joint Surg. 1963; 45A: 925-33

[10] Lopez-Vazquez,.E, Juan, J.A., Vila, E., Debon, J. RECONSTRUCTION OF ANTERIOR CRUCIATE LIGAMENT WITH A DACRON PROSTHESIS VOL. 73-A, NO. 9,OCTOBER 1991, pp.1294-1300, Journal of Bone and Joint Surgery
[11] Marshall J, Rubin R. Instability of the knee. A long term experimental study in dogs. JBJS(Am). 1971;534A:1561.

[12] Michael Wagner, Max J. Kääb, Jessica Schallock, Norbert P. Haas and Andreas Weiler Hamstring Tendon Versus Patellar Tendon Anterior Cruciate Ligament Reconstruction Using Biodegradable Interference Fit Fixation Am J Sports Med 2005 33: 1327

[13] Muneta T, Sekiya L, Yagishita K et al Double bundle reconstruction of the ACL using semitendinosus with endobutton Operative Technique and Preliminary Results Arthroscopy. 1999;618 - 624

[14] Noyes, F. R and Barber-Westin, S.D. RECONSTRUCTION OF ANTERIOR CRUCIATE LIGAMENT WITH HUMAN ALLOGRAT; COMPARISION OF EARLY AND LATE RESULTS. VOL. 78-A, NO. 4,APRIL 1996, pp.524-537, Journal of Bone and Joint Surgery.

[15] O,Brien, S.J.,Warren,R.F.,Pavlov,H., Panariello, R.,Wickiewicz,T.L. RECONSTRUCTION OF THE CHRONICALLY INSUFFICIENT ANTERIOR CRUCIATE LIGAMENT WITH THE CENTRAL THIRDOF THE PATELLAR LIGAMENT VOL. 73-A, NO. 2,FEBRUARY 1991, pp.278-286, Journal of Bone and Joint Surgery

[16] Prospective Randomized Clinical Evaluation of Conventional Single-Bundle, Anatomic Single-Bundle, and Anatomic Double-Bundle Anterior Cruciate Ligament Reconstruction: 281 Cases with 3-to 5-Year Follow-up. Am J Sports Med. 2012 Mar;40(3):512-20.

[17] Rosenberg TD, Franklin JL, Baldwin GN, Nelson KA. Extensor mechanism function after patellar tendon graft harvest for anterior cruciate ligament reconstruction. Am J Sports Med. 1992;24(5): 698-704.

[18] Sapega,A.A,Moyer,R.A.,Schneck,C.,

Komalahirayana,N TESTING FOR ISOMETRY DURING THE RECONSTRUCTION OF THE ANTERIOR CRUCIATE LIGAMENT ANATOMICAL AND BIOMETRIC CONSIDERATIONS. VOL. 72-A, NO. 2,FEBUARY 1990, pp.259-267, Journal of Bone and Joint Surgery.

[19] Sebastian Kopf, Brian Forsythe, Andrew K. Wong, Scott Tashman, William Anderst, James J. Irrgang and Freddie H. Fu Nonanatomic Tunnel Position in Traditional Transtibial Single-Bundle Anterior Cruciate Ligament Reconstruction Evaluated by ThreeDimensional Computed Tomography. Journal of Bone \& Joint Surgery. 2010;92:1427-31

[20] Shugo Maeda, Yoshimasa Fujimaki, Bart Muller,Paulo H. Araujo and Freddie H. Fu, Individualized Anatomic Anterior Cruciate Ligament Reconstruction.arthroscopy Techniques, Vol 1, No 1 (September), 2012: pp e23-e29

[21] Takagi K. The classic Arthroscop. Cliri Orthop Related Res. 1982; 167:6- 8. Campbell WC. Repair of the ligaments of the knee. Surg Gynecol Obstet. 936; 62: 964-70.

[22] Campbell's Operative manual of orthopedics, Volume 2 Page No. 2257-2299. Technique of arthroscopic ACL Reconstruction. 
International Journal of Science and Research (IJSR)

ISSN (Online): 2319-7064

Index Copernicus Value (2013): 6.14 | Impact Factor (2014): 5.611
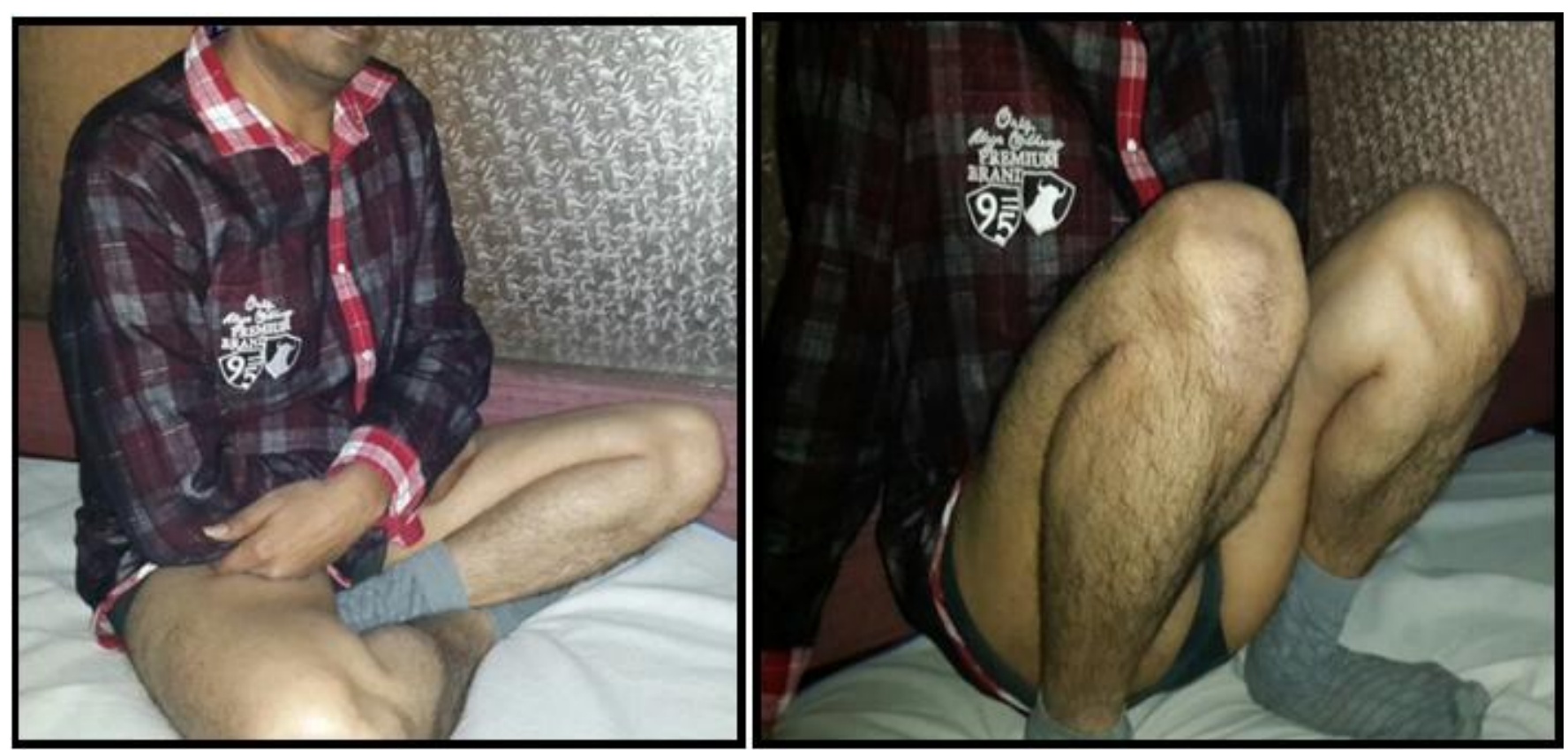

Name : Mahesh Sheth

Age / Sex : 30 Year/ Male

Occupation : Working at Private Firm

Date of Operation : 19/09/2009

Mode of Injury : Sports

Mechanism of Injury - Vulgus - ER

Operative Details -

Tibial Tunnel $-10 \mathrm{~mm}$

Femoral Tunnel $-10 \mathrm{~mm}$

Medial Meniscus - Normal

Lateral Meniscus - Normal

PCL - Normal

Scar Condition - Good

Post Operative Complication - No Complication

Range of Motion- 0 - 130

Patient can able to Squat and sit cross leg

Lysholm's Score - 95

Result - Excellent 